\title{
Efek Perbedaan Kerapatan Media Substrat Terhadap Proses Penempelan Larva Tiram Mutiara (Pinctada maxima)
}

\author{
Raismin Kotta ${ }^{1 \square}$ \\ ${ }^{1}$ Peneliti Pusat Penelitian Oseanografi-LIPI, Indonesia. Email : raisminkotta88@gmail.com
}

УInfo Artikel:

Diterima : 23 Mei 2018

Disetujui : :07 Jui 2018

Dipublikasi : 29 Juli 2018

琴Artikel Penelitian

Keyword:

Perbedaan Kerapatan media substrat, larva tiram mutiara

$\triangle$ Korespondensi:

Raismin Kotta

Peneliti Pusat Penelitian Oseanografi-LIPI. Indonesia.

Email: raisminkotta88@gmail.com cc)(i) (2) AGRIKAN
Abstrak. Usaha budidaya kerang mutiara lebih banyak terarah pada kegiatan pembesaran dan produksi mutiara, sehingga kebutuhan akan spat sebagai bahan baku utama semakin meningkat. Penelitian telah dilakukan pada bulan oktober 2017 di Laboratorium Balai Pengembangan Perikanan Pantai Sekotong Lombok Barat menggunakan metoda eksperimen.Tujuan Penelitian ini adalah untuk mengetahui perbandingan kerapatan media kolektor yang berbeda terhadap proses penempelan yang lebih efektif pada larva tiram mutiara fase plantygrade di laboratorium. Hasil yang di peroleh pada perlakuan P2 Media substrat/kolektor kerapatan $80 \%$ sangat baik dan cukup padat yaitu sebanyak 370 ekor spat/substrat. Sedangkan penempelan spat terendah ditemukan pada perlakuan P1 Media kolektor kerapatan 50\% sebanyak 217 ekor spat/substrat. Dapat disimpulkan bahwa semakin lebar kerapatan media kolektor maka semakin kecil proses penempelan larva fase plantygrade. Berdasarkan analisis statistik bahwa kerapatan 50\% perlakuan P1 dan perlakuan P2 menunjukan adanyan berbeda nyata, dimana Thitung $(1,561)<$ Ttabel (2.228) ini berarti penempelan larva menggunakan substrat/kolektor kerapatan $50 \%$ dengan $80 \%$ yang berbeda tetapi tidak berpengaruh pada penempelan larva tiram mutiara fase plantygrade. Hasil pengamatan nilai rata-rata kualitas perairan seperti; Suhu 28,9 0C, pH 7,1, Salinitas 33 ppt, dan DO 5,9 ppm. Pemberian jenis pakan alami terhadap tiram mutiara pada fase plantygrade antara lain yaitu fitoplankton jenis Isochrysis galbana, Chaetoceros simplex dan Nannoclhoropsis sp.

\section{PENDAHULUAN}

Tiram mutiara (Pinctada maxima) merupakan salah satu sumberdaya biota laut yang memiliki nilai ekonomis dan estetika tinggi. Hampir semua bagian tubuh dari organisme ini (cangkang dan butiran mutiara) dapat di jual dan diminati oleh konsumen. Dalam kondisi hidup, Pinctada maxima dapat dijual dalam bentuk spat atau induk, dan dalam bentuk butiran mutiara memiliki nilai ekonomis penting dengan nilai jual yang tinggi dan mahal. Disamping itu cangkang tiram mutiara dapat dijadikan sebagai bahan kosmetik dan berbagai barang kerajinan tangan. Melihat dari nilai dan manfaatnya tersebut serta ketersediaannya di alam yang semakin terbatas, maka perlu dikembangkan teknik budidaya tiram mutiara untuk mendapatkan kualitas mutiara yang terbaik (Anonim, 2010).

Usaha budidaya tiram mutiara di indonesia lebih banyak terarah pada kegiatan pembesaran dan produksi mutiara, sehingga kebutuhan akan spat sebagai bahan baku utama semakin meningkat. Disisi lain pasokan benih berasal dari hasil tangkapan di alam dengan ukuran, umur, serta kualitas yang beraneka ragam dan sulit diperoleh menyebabkan perusahaan budidaya mutiara mengalami kendalah dalam pengaturan rencana reproduksi dan pemeliharaan (Hasan, 1999 dalam Antoro $d k k ., 2001)$.

Kendala utama pada produksi tiram mutiara saat ini adalah produksi benih spat dan pertumbuhan yang lambat serta sintasan rendah dalam pemeliharaan larva dan spat. Sintasan dan larva (D1) sampai menjadi spat berukuran $2-3 \mathrm{~cm}$ sekitar $0,05 \%$ dan untuk mencapai ukuran $2-3 \mathrm{~cm}$ diperlukan waktu pemeliharaan 3-4 bulan. Menurut Chan (1949) dalam Winanto (2009) pertumbuhan tiram biasanya dilihat dari pertumbuhan ukuran cangkang yang dapat diukur dari berat, lebar (DV), panjang (AP), tebal dan panjang garis engsel (hinge ligament). Pertumbuhan cangkang tiram mutiara juga 
dipengaruhi oleh kualitas perairan budidaya sebagaimana dikatakan Sutaman (1993) bahwa faktor biofisik-kimia lingkungan yang berperan dalam pertumbuhan tiram mutiara antara lain adalah suhu perairan, salinitas, $\mathrm{pH}$, makanan dan unsur kimia dalam air laut.

Mengantisipasi permasalahan tersebut maka penyediaan benih/spat tiram mutiara dari hasil pembenihan merupakan solusi terbaik guna mengatasi kelangkaan dalam pembenihan penyediaan benih yang tepat mutu dan jumlah. Benih tiram mutiara dari hasil pembenihan biasanya mempunyai ukuran yang seragam tersedia dalam jumlah yang cukup dan berkesinambungan, sehingga saat operasi dan panen dilakukan dapat lebih seragam dalam jumlah sesuai keinginan, di samping itu juga yang lebih penting adalah kelangsungan usaha budidaya dapat lebih terjamin, namun sayangnya usaha pembenihan dan pembesaran masih jarang di lakukan karena keterbatasan teknologi dan investasi (Winanto, 1999).

Salah satu kegiatan yang banyak menyita waktu dan perhatian dalam kegiatan pembenihan tiram mutiara adalah fase larva, dimana pada fase umbo sampai spat sangat rentan terhadap penyakit yang dapat mengakibatkan kematian. Periode pemeliharaan larva sebenarnya dimulai dari larva stadia D, atau setelah berakhirnya stadia trocopore sampai stadia pediveliger atau plantygrade (Winanto $d k k ., 2001$ ).

Pada fase spat, bak pemeliharaan larva dilengkapi dengan media penempelan berupa kolektor berukuran $30 \times 40 \mathrm{~cm}$ dari bahan PE (Polyethylene) dengan cara digantungkan pada permukaan badan air di bak pemeliharaan (bak kolektor). Fase perkembangan larva terdiri dari fase D-Shape, umbo, pediveliger, plantigrade, dan spat. Tingkat kelangsungan hidup berturut-turut adalah $80 \%$ (HR), 95\%, 75\%, 20\%, 10\%, 2,3\%, 2\% (SR). Sedangkan pertumbuhan larva untuk fase $D$ Shape berkisar 60-180 $\mu \mathrm{m} 13$ hari, Umbo 180-230 $\mu \mathrm{m}$, Pediveliger 220-230 $\mu \mathrm{m}$, plantigrade 230-270 $\mu \mathrm{m}$, dan fase spat $270-2500 \mu \mathrm{m}$ (Rahman, 2001).

Pada fase peralihan yakni fase plantigrade menjadi spat, sifat hidupnya akan cenderung menempel pada substrat. Oleh karena itu, larva yang mulai tumbuh menjadi spat harus diberikan substrat agar tidak menempel pada bak pemeliharaan. Substrat yang digunakan biasanya terbuat dari tali PE atau orcid net dengan kerapatan 80-90\% (Laksana, 2011).
Larva tiram mutiara lebih menyukai tempat yang gelap atau remang-remang daripada terang. Untuk itu, pemeliharaan larva diusahakan ditutup dengan plastik gelap. Sedangkan kepadatan larva yang baik \pm 200 ekor/kolektor. Kepadatan yang tinggi akan mengurangi pertumbuhan normal (Aprisanto $d k k$., 2008). Hasil penelitian Taylor $d k k$, (1997) Menunjukan bahwa, kelangsungan hidup spat tiram mutiara yang terbaik adalah pada padat tebar 10 juvenil per slat dengan ukuran spat $75 \mathrm{x}$ $500 \mathrm{~mm}^{2}$. Penelitian ini bertujuan untuk mengetahui perbandingan kerapatan media kolektor yang berbeda terhadap proses penempelan yang lebih efektif pada larva tiram mutiara fase plantygrade.

\section{BAHAN DAN METODE}

Penelitian ini dilaksanakan pada bulan maret 2018 di Balai Pengembangan Budidaya Perikanan Pantai (BPBPP), Kecamatan Sekotong Kabupaten Lombok Barat. Alat yang digunakan antara lain Styrofoam, Planton net, Blower, Beker Glass, Kamera, Sandfilter, Tali Nylon, Microscope, Batu, Bak, Penggaris, Thermometer, LUP, pH, Refratometer, dan bahan yang digunakan berupa chlorin, air laut, induk tiram mutiara, planton, pupuk KW 21, Larutan HCI, Na-thiosulfat, Kolektor (a: kerapatan 50\% dan b: kerapatan $80 \%$ ).

Cara kerja untuk persiapan penelitian pertama-tama air laut di ambil dan diendapkan selama 1 hari, selanjutnya air yg sudah diendapkan diberi perlakuan atau treatment dengan tujuan agar air tersebut layak digunakan sebagai media hidup larva fase plantygrade. Tahap awal sebelum percobaan dimulai dilakukan seleksi induk dan kultur plankton. Pada saat jumlah plankton sudah mencukupi untuk kebutuhan produksi spat, maka induk-induk dibawa ke lab untuk dipijahkan. Induk dipijahkan di dalam aquarium (100 L), setelah induk memijah selanjutnya dilakukan pemanenan telur. Telur yang telah bersih diseleksi dan dipelihara di dalam bak penetasan volume $1 \mathrm{~m} 3$, yang sekaligus berfungsi sebagai bak pemeliharaan larva. Jadwal pemberian pakan dan pengelolaan air mengacu pada percobaan Winanto (2004). Pada waktu larva berusia 16 hari, di dalam bak pemeliharaan larva dipasang kolektor dari bahan paranet $(40 \times 60 \mathrm{~cm})$.. Dalam penelitian ini media penempelan menggunakan substrat monofilamen dengan ukuran berbeda ( $P_{1} 50 \%$ dan $P_{2} \quad 80 \%$ ) dan media pemeliharaan mengunakan styrofoam volume 30 liter, kemudian disiapkan 
selang ${ }^{1 / 2}$ inci dan planton net dengan ukuran 200 $\mu \mathrm{m}$.

Penelitian ini menggunakan metode eksperimen, dimana teknik pengumpulan data yaitu berupa data primer dengan cara observasi langsung, dan data sekunder bersumber dari referensi pendukung berupa literatur, jurnal, laporan instansi serta dinas kelautan setempat. Untuk analisis data mengunakan statistik Rancangan Acak Lengkap (RAL) dengan 2 (dua) perlakuan yang masing-masing 6 kali ulangan.

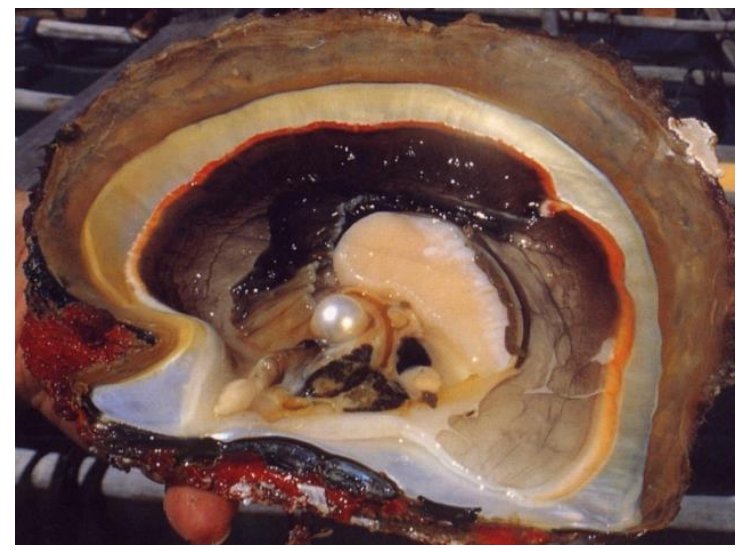

1. Biologi Kerang Mutiara (Pinctada maxima)

Menurut Sutaman (1993), Klasifikasi tiram metiara (Pinctada maxima) adalah sebagai berikut :

Filum

Kelas

Ordo

Family

Genus

Spesies
: Mollusca

: Pellecypoda

: Anysomyaria

: Pteridae

: Pinctada

: Pinctada maxima

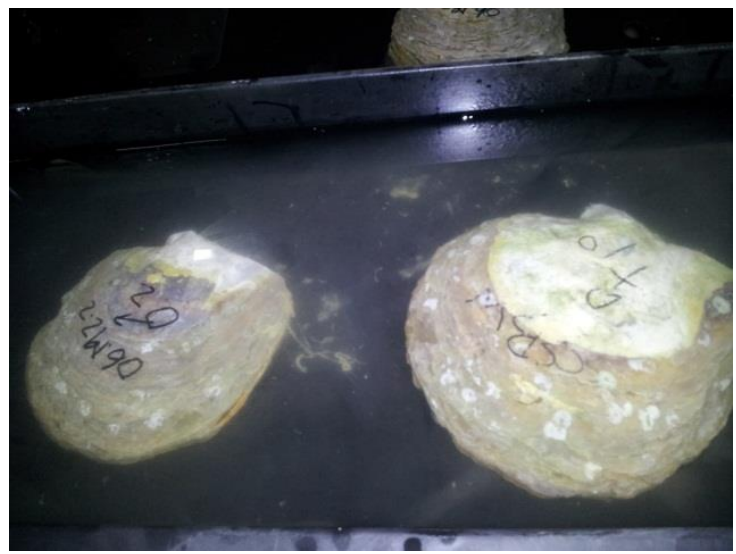

Gambar 1. Induk Tiram mutiara (Pinctada maxima, Anonim, 2012)

Klasifikasi jenis-jenis tiram mutiara dapat dilakukan berdasarkan bentuk (sosok), cara hidup, penyebaran, Zat mutiara yang dihasilkan, ukuran dan warna cangkang. Bentuk cangkang membedakan antara genus Pinctada dan Pteria, sedangkan warna dan garis cangkang membedakan spesies-spesies Pinctada maxima, Pinctada margaritifera, Pinctada chemnitis, (Sutaman, 1993). Diantara tiram penghasil mutiara tersebut, Pinctada maxima merupakan tiram penghasil mutiara terbaik di Indonesia dan dunia karena butiran mutiara yang dihasilkan berukuran paling besar (Mulyanto, 1987 dalam Ditjenkan 2012).

Spesies Pinctada maxima mempunyai ukuran dorso-ventral dan anterior-posterior yang hampir sama, sehingga bentuknya agak bundar. Bagian dorsal berbentuk datar dan panjang serta dihubungkan dengan semacam engsel berwarnah hitam, selain itu memiliki gonad yang berbentuk tebal menggelembung. Pada kondisi matang gonad menutupi seluruh tubuh, kecuali bagian kaki. Pada stadia pediveliger ditandai dengan perkembangan bysus yang berfungsi untuk bergerak, berenang dan menempel (Takemura dalam Winanto et al., 2009). a. Stadia Veliger/D-Shape .

Stadia veliger merupakan awal dari pertumbuhan larva. Stadia veliger atau disebut juga D-shape ini terjadi setelah kurang lebih 22 jam proses embryogenesis. Sebagaimana menurut Winanto (2009) sekitar 22 jam setelah menetas ditemukan larva yang bagian lambungnya sudah berwarna, sehingga diduga pada saat ini organ pencernaan sudah ada dan larva pertama kali makan. Larva mulai pertama kali makan ketika berumur 22-24 jam setelah menetas. Perkembangan stadia veliger menurut Tanaka dan Kumeta (1981) ditandai dengan adanya formasi garis engsel, mantel, silia-silia pada velum dan hilangnya apical flagellum, pita-pita silia pada bagian luar lubang mulut (preoral) dan setelah lubang mulut (preoral).

b. Stadia Pediveliger.

Stadia Pediveliger merupakan stadia umbo akhir dengan ditandai berkembangnya organ kaki yang berfungsi untuk bergerak dan berenang. Stadia inilah larva mulai aktif mencari tempat menempel. Pada stadia ini merupakan fase transisi dari plantonik ke benthik dengan terbentuknya primordia kaki, sehingga kondisi kesehatannya terganggu yang 
berdampak pada kurangnya nafsu makan. Larva akan bergerak aktif mencari substrat, dimana hal ini merupakan fase kritis larva. Jika pada fase ini tidak ditemukan substrat/kolektor yang cocok sebagai tempat penempelan larva, maka mortalitas tidak akan terhindarkan.

c. Peroses Penempelan Larva Fase Plantygrade

Perkembangan larva tiram mutiara pada fase plantygrade dicapai setelah larva berumur 20-22 hari. Ditandai dengan tumbuhnya cangkang baru sepanjang pripheri dan memproduksi benang-benang bysus untuk menempelkan diri pada substrat. Penempelan adalah proses tingkah laku yang ditujukan oleh larva fase akhir. Pada mulanya larva menggunakan kakinya untuk berenang dan bergerak perlahan-lahan saat akan saat akan menempel pada substrat. Jika jenis substrat yang di tempati cocok maka larva akan menempel. Secara keseluruhan proses ini disebut menempel (settle/setting) atau periode spatfall, Tjahjo, (2004). Secara umum bahan substrat/kolektor yang baik yaitu tidak mengeluarkan senyawa kimia jika bereaksi dengan air laut, menarik minat spat untuk menempel, dan tidak menganggu pertumbuhan (Winanto, 2004).

d. Pemeliharaan Larva Fase Plantygrade

Pada fase Plantygrade ini media yang digunakan sebagai tempat menempel spat adalah substrat /kolektor berwarna hitam berbahan polycarbonat dengan ukuran $14 \mathrm{~cm} \mathrm{x}$ $13 \mathrm{~cm}$. Penggantungan substrat/kolektor dilakukan setelah larva masuk fase plantygrade yang ditandai munculnya titik hitam (eye spot). Larva dibiarkan menempel dengan sendirinya pada substrat/kolektor yang telah disediakan di styrofoam berukuran 30 liter. Setiap 2 kali sehari larva di cek dengan menggunakan mikroskop.

Tahap selanjutnya adalah pengelolaan kualitas air dilakukan dengan cara menganti air secara total 1-2 hari sekali. Selain pergantian air secara total diperlukan penyiponan pada dasar bak dengan tujuan larva yang kurang sehat yang mengendap pada dasar bak supaya tidak tercampur dengan larva yang sehat. Air yang akan di ganti disedot menggunakan selang secara bertahap dengan cara mengambil larva yang ada di permukaan air terlebih dahulu karena larva yang cenderung diatas lebih sehat jika dibandingkan dengan yang berada dibawah atau dasar dan apabila ada gejala kurang sehat atau pada masa kritis diperlukan penyaringan larva secara terus menerus agar bisa mengurangi kematian massal. Setelah larva tersaring, kemudian dimasukan ke dalam bak 30 liter yang terisi air baru yang telah melalui sandfilter. Pergantian air ini dilakukan sampai larva siap menempel yakni masuk pada fase plantygrade dengan ukuran larva kurang lebih $200 \mu \mathrm{m}$.

\section{Parameter Pengamatan}

Parameter utama dalam pelaksanaan penelitian ini adalah penempelan larva fase plantygrade dari masing-masing perlakuan. Salah satu metode yang digunakan untuk menentukan jumlah larva yang menempel dengan cara manual/menghitung secara langsung. Perhitungan dilakukan 2 kali, dimulai pada hari ke 12 dan hari ke 15 untuk memastikan jumlah keseluruhan larva yang menempel. Parameter penunjang atau data pendukung yaitu faktor kualitas air yang meliputi salinitas, suhu, DO, dan $\mathrm{pH}$.

Dalam kegiatan pemeliharaan larva sampai spat membutuhkan fitoplankton sebagai makanan utamanya. Makanan utama larva tiram mutiara adalah jenis alga. Oleh karena itu tiga hari sebelum telur menetes, pakan perlu disiapkan sebagai makanan awal larva. Biasanya jenis alga yang digunakan adalah Isochrysis galbana dan Monochrysis lutheri Sutaman, (1993). Menurut Aprisanto dkk., (2008) larva mulai diberi pakan setelah mencapai fase D-Shape (D1). Pakan yang diberikan berupa fitoplanton jenis Isochrysis galbana, Chaetocheros gracilli dan Nannoclhoropsis sp. Pakan yang diberikan ditambahkan dengan fitoplanton jenis Nitzchia sp dan Tertaselmis chuii setelah mencapai fase umbo 3. Untuk melihat kondisi larva dengan mikroskop selama 4 jam sebelum dan sesudah larva diberi pakan.

Keseluruhan hasil penelitian terkait penempelan larva dan spat pada substrat/kolektor akan dianalisa menggunakan Uji $\mathrm{T}$ tes dimana uji statistic guna menguji parameter pengamatan dengan menggunakan sampel terkecil kurang dari 30 sampel (Natsir M., 1993). Untuk menentukan berbeda tidaknya kedua macam perlakuan yaitu $(\mathrm{P} 1=$ substrat/kolektor kerapatan $50 \%$ dan $\mathrm{P2}=$ substrat/kolektor kerapatan $80 \%$ ) maka digunakan Ttabel. Data hasil proses penempelan kemudian dianalisa menggunakan formulasi uji $T$ tes. 
sebanyak 217 ekor sedikit berkurang jumlahnya dibandingkan pada perlakuan P2. Untuk lebih jelas jumlah larva/spat yang menempel dapat dilihat pada tabel berikut ini ; Tabel. Kerapatan media substrat/kolektor yang berbeda terhadap proses penempelan larva/spat tiram mutiara (Pinctada maxima) fase plantygrade.

Hasil penelitian ini menunjukan bahwa semakin lebar kerapatan terhadap media kolektor maka semakin kecil pengaruhnya dalam proses penempelan larva pada fase plantygrade, dengan demikian maka dapat dikatakan bahwa perlakuan P2 dengan media substrat/kolektor kerapatan $80 \%$ yang terbuat dari bahan polycarbonat adalah yang terbaik dibandingkan perlakuan P1 dengan media kolektor kerapatan $50 \%$ berbahan polycarbonat yang sama. Namun perlu diwaspadai juga bahwa pada kepadatan tinggi terjadi kompetisi pakan dan ruang yang tinggi pula. Ruang yang terbatas, menyebabkan posisi spat saling berhimpitan sehingga dikhawatirkan dalam masa pertumbuhannya kelak, pertumbuhan cangkang menjadi tidak normal. Hal ini dapat terjadi karena pertumbuhannya terhambat oleh spat lain yang ukurannya lebih besar dan atau posisinya menempel di bagian paling bawah. Spat-spat yang menempel pada cangkang spat lain yang ukurannya lebih besar, umumnya pertumbuhannya juga lambat dan bentuknya tidak normal. Ratio antara pertumbuhan panjang dorso-ventral (tinggi) dibanding antero-posterior (panjang) akan mengalami penurunan seiring dengan meningkatnya kepadatan. Hal ini mengindikasikan tingkat kepadatan tidak hanya mempengaruhi laju pertumbuhan individu umumnya tetapi juga cara individu tersebut tumbuh.

\begin{tabular}{lccc}
\hline Ulangan & \multicolumn{2}{c}{ Jumlah Larva/spat Menempel } & Jumlah \\
\hline 1 & P1 (50\%) & P2 (80\%) & \\
2 & 37 & 50 & 87 \\
3 & 34 & 61 & 95 \\
4 & 40 & 67 & 107 \\
5 & 35 & 60 & 95 \\
6 & 38 & 70 & 108 \\
\hline Total & 33 & 62 & $95-$ \\
Rata-rata & 217 & 370 & 587 \\
Kisaran & 36,17 & 61,67 & 97,84 \\
\hline
\end{tabular}

Berkaitan dengan laju pertumbuhan larva menjadi spat, hasil penelitian lainpun menunjukkan bahwa semakin tinggi tingkat kepadatan, maka laju pertumbuhan makin lambat. Menurut Gosling (2004) sebagian besar peneliti menerangkan bahwa tingkat kepadatan merupakan modulator pertumbuhan. Beberapa peneliti juga telah melakukan pengujian pengaruh berbagai kisaran tingkat kepadatan pada setiap stadia dalam siklus hidup bivalvia, namun demikian hasil laju pertumbuhan yang diamati dapat berbeda tergantung pada spesies dan lingkungan serta media pemeliharaan. Berdasarkan analisis statistik menggunakan uji $\mathrm{T}$ tes pada taraf $5 \%(0,05)$ dapat diketahui bahwa jumlah hasil penempelan larva/spat pada substrat/kolektor perlakuan P1 dan P2 menunjukan adanya berbeda Nyata, dimana $T$ hit $(1,561)<T$ tab $(2,228)$. Hal ini diartikan bahwa penempelan larva/spat dengan menggunakan substrat/kolektor kerapatan $50 \%$ dan kerapatan $80 \%$ berbeda tetapi tidak berpengaruh pada penempelan larva/spat tiram mutiara fase plantygrade.

Di dalam kegiatan pembenihan tiram mutiara, faktor lingkungan seperti Suhu, Salinitas, pH dan DO merupakan faktor lingkungan yang harus di perhatikan jika tidak ingin gagal dalam kegiatan budidaya. Suhu air sangat berperan dalam mengendalikan proses metabolisme yang menyebabkan pertumbuhan tiram akan lebih baik. Suhu memegang peranan penting bagi pertumbuhan tiram dan pembentukan lapisan mutiara. Menurut Winanto, (2004) bahwa, suhu air pada kisaran $27-31{ }^{\circ} \mathrm{C}$ juga dianggap layak untuk tiram mutiara. Pada umumya, suhu yang baik untuk kelangsungan hidup tiram mutiara berkisar antara 25-30 ${ }^{\circ} \mathrm{C}$. Rata-rata suhu yang digunakan selama penelitian adalah $28,9{ }^{\circ} \mathrm{C}$. $\mathrm{pH}$ substrat sangat erat hubungannya dengan bahan organik substrat dan tipe substrat . Efendi, (2003) dalam Eric (2008), menyatakan bahwa jika perairan mengandung karbondioksida bebas dan ion karbonat maka $\mathrm{pH}$ cenderung asam, dan $\mathrm{pH}$ akan 
kembali cenderung meningkat jika $\mathrm{CO}_{2}$ dan $\mathrm{HCO}_{3}$ mulai berkurang. Rata-rata nilai $\mathrm{pH}$ yang diperoleh selama penelitian adalah 7,1 . Menurut Priyambodo, (2012) bahwa habitat tiram mutiara diperairan adalah dengan $\mathrm{pH}$ lebih tinggi dari 6,75. Tiram tidak akan dapat berproduksi lagi apabila pH melebihi 9,00. Aktivitas tiram akan meningkat pada $\mathrm{pH} 6,75-7,00$, dan menurun pada $\mathrm{pH} 4,00-6,5$. Kondisi yang sama berlaku juga pada salinitas. Tiram mutiara sangat toleran terhadap perubahan salinitas karena hewan ini termasuk Euryhaline artinya hewan ini dapat hidup pada kisaran salinitas yang lebar. Rata-rata nilai salinitas yang diperoleh pada saat penelitian adalah 33 ppt. Kadar salinitas tersebut merupakan yang optimal sebagai tempat hidup larva tiram mutiara (Pinctada maxima) fase plantygrade. Menurut Winanto, (2004). Bahwa tiram mutiara dapat hidup pada salinitas 24 ppt hingga 50 ppt untuk jangka waktu yang pendek, yaitu 2 sampai 3 hari. Sedangkan pemilihan lokasi sebaiknya di perairan yang memiliki salinitas antara 32-35 ppt. Kondisi ini baik untuk pertumbuhan dan kelangsungan hidup tiram mutiara (Pinctada maxima). Oksigen terlarut (DO) umumnya menjadi faktor pembatas bagi sintasan organisme aquatik. Oksigen terlarut biasanya digunakan juga sebagai indikator pencemaran suatu perairan. Apabila kadar oksigen terlarut sangat rendah dari batas bawah yang dibutuhkan biota air maka perairan tersebut tercemar. Perairan yang biasa digunakan untuk kegiatan budidaya perikanan sebaiknya memiliki kadar oksigen terlarut sebesar 5 mg/l, jika kurang dari $4 \mathrm{mg} / \mathrm{l}$ akan menimbulkan efek yang merugikan bagi semua biota air termasuk tiram mutiara. Hasil penelitian Dharmaraj et al,1987 dalam Budianto $M$, (2011) tentang kebutuhan oksigen terlarut titam mutiara, menunjukan bahwa tiram berukuran $40-50 \mathrm{~mm}$ mengonsumsi oksigen $1,339 \mathrm{~mL} / \mathrm{jam}$, ukuran $50-60 \mathrm{~mm}$ mengonsumsi 1,650 mL/jam dan ukuran 60-70 mm mengonsumsi $1,810 \mathrm{~mL} / \mathrm{jam}$. Menurut Winanto, (2009), Oksigen terlarut menjadi faktor pembatas kelangsungan hidup dan perkembangannya. Tiram mutiara akan dapat hidup baik pada perairan dengan 5,2-6,6 ppm. Rata-rata DO yang diperoleh selama penelitian adalah 5,9 ppm. Keseluruhan nilai kualitas air yang diperoleh pada saat penelitian masih dalam ambang batas kewajaran untuk budidaya tiram mutiara (Pinctada maxima) dengan nilai seperti dapat dilihat pada grafik Gambar 2.

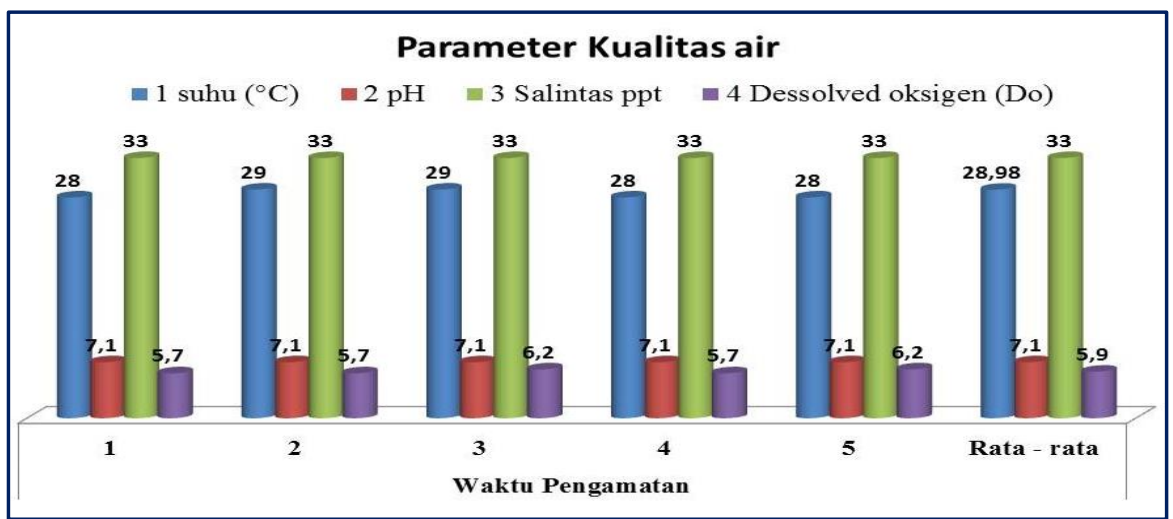

Gambar 2. Grafik kualitas air (Suhu, pH, Salinitas, DO) selama penelitian

Dalam kegiatan budidaya tiram mutiara, faktor ketersediaan makanan merupakan hal yang sangat menentukan bagi keberhasilan usaha. Makanan umum larva tiram mutiara adalah dari jenis mikro alga (fitoplankton). Biasanya sebelum memulai kegiatan hatchery, fitoplankton sudah di kulturkan sebagai makanan selama di laboratorium. Kepadatan pakan alami yang baik untuk larva tiram mutiara adalah kira-kira 200 ekor larva/liter. Kepadatan terlalu tinggi akan mengurangi pertumbuhan normal, bahkan bisa mengakibatkan kematian.
Diduga pada kondisi kepadatan optimum larva ataupun spat dapat tumbuh dan berkembang lebih baik karena kompetisi ruang dan pakan relatif kecil. Sebaliknya pada kepadatan terlalu tinggi (500-600 ekor/kolektor) terjadi kompetisi pakan dan tempat yang lebih tinggi, sehingga larva dan spat spat yang aktif mendapatkan pakan akan hidup dan tumbuh pesat, sebaliknya yang pasif akan tumbuh lambat atau bahkan mati. Sama halnya dengan persaingan tempat, karena larva dan spat termasuk hewan yang hidup menetapmenempel pada substrat, maka jika kepadatan terlalu tinggi perkembangan cangkangnya akan 
terganggu, karena ruang tumbuh terbatas dan cangkang saling berhimpitan antara satu dengan yang lain. Pada penelitian dengan kepadatan diatas 500 ekor per substrat/kolektor ditemukan spat menempel bergerombol, saling melekat antara satu dengan yang lain. Hal ini mengakibatkan pertumbuhan jadi terhambat dan spat yang tertindih di bawah sering ditemukan mati atau jika hidup ukurannya lebih kecil dari pada yang berada di atas. Dalam penelitian Taylor et al. (1997) juga menemukan hal yang sama, yaitu pada tingkat kepadatan tinggi ( $\geq 25$ individu per $100 \mathrm{~cm} 2)$ individu saling melekat bersama membentuk kelompok. Kebiasaan suka bergerombol semakin nyata pada tingkat kepadatan yang tinggi.

Jika tingkat kepadatan yang digunakan dalam kajian ini dikonversi dengan hasil penelitian Taylor et al., (1997) yaitu "kepadatan individu per $100 \mathrm{~cm} 2$ ", maka hasilnya hampir sama dengan penelitian Rose and Baker (1994) yaitu pada tingkat kepadatan 4 individu per $100 \mathrm{~cm} 2$ dan 25 individu per $100 \mathrm{~cm} 2$ (kultur di dasar) dan tingkat kepadatan 3 individu per $100 \mathrm{~cm} 2,7$ individu per $100 \mathrm{~cm} 2$.(metode gantung di laut) Hasilnya sintasan 98-99\% (kultur di dasar) pada tingkat kepadatan 4 individu per $100 \mathrm{~cm} 2$ dan tidak berbeda nyata.dengan 25 individu per 100 cm2. Sintasan dengan metode gantung 88-91 \%. Sintasan tersebut lebih tinggi dibandingkan hasil kajian ini dan hasil penelitian Taylor et al. (1997).
Lebih lanjut Taylor et al. (1997) menyampaikan bahwa hasil sintasan dapat berbeda karena adanya perbedaan lokasi penelitian, musim dan metode budidaya. Berdasarkan hasil kajian dapat disampaikan bahwa semakin tinggi tingkat kepadatan, maka sintasan makin rendah.

Tiram mutiara cenderung menyukai tempat yang gelap atau remang-remang daripada yang terang, oleh karena itu tempat pemeliharaan larva sebaiknya dalam ruang yang tertutup dari sinar/cahaya. Dalam penelitian ini jenis pakan alami yang digunakan terdiri dari Isochrysis galbana, Chaetocheros simplex dan Nannochloropsis sp. Hasil yang dipeoleh menunjukan peningkatan lajupertumbuhan larva dan spat sampai pada fase pediveliger dimana larva menjadi spat dan siap menempel pada substrat/kolektor. Kondisi spat memperlihatkan ciri-ciri tiram yang sehat ditunjukan dari bentuk,warna dan kepadatan menempel/settle. Menurut Winanto (2001) bahwa, ada beberapa jenis alga yang digunakan untuk pakan larva tiram mutiara yaitu jenis Nannoclhoropsis, Isochrysis galbana, Pavlopa lutheri maupun Chaetocheros sp. Pemberian pakan dilakukan setelah terlebih dahulu dilakukan pengecekan kepadatan planton hasil kultur, kondisi larva tiram mutiara, dan medium pemeliharaannya. Berikut ini adalah grafik jenis pakan alami yang digunakan selama penelitian.

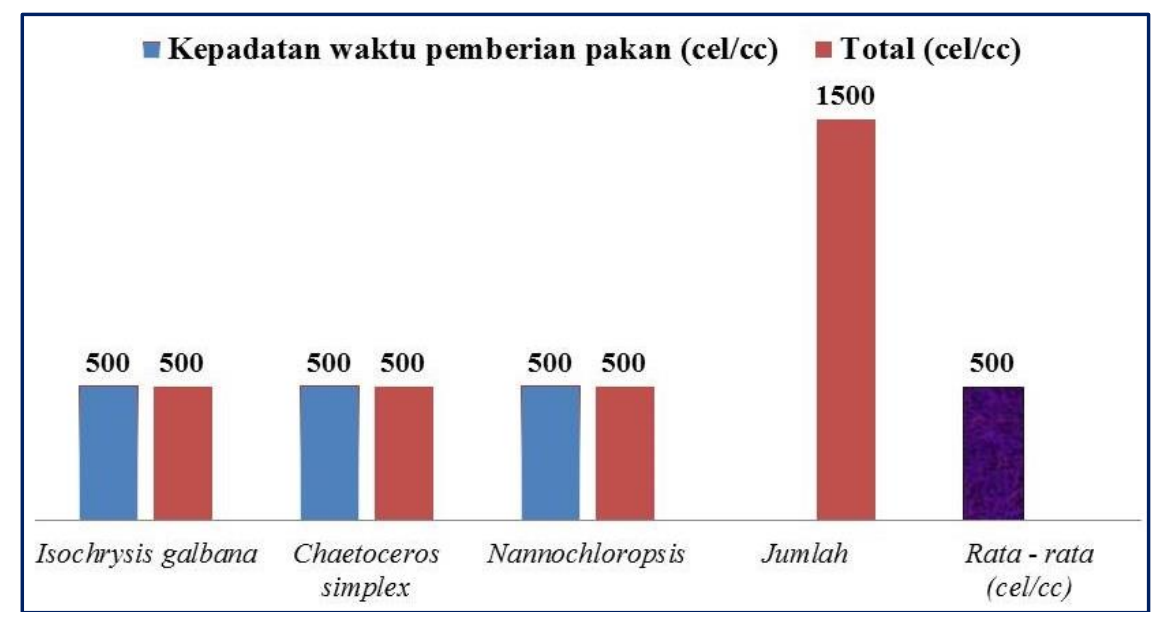

Gambar 3. Jenis pakan alami yang digunakan selama penelitian.

\section{PENUTUP}

Dari hasil penelitian dapat diambil kesimpulan bahwa pengaruh kerapatan media kolektor terhadap proses penempelan larva tiram mutiara (Pinctada maxima) pada fase plantygrade yang tinggi terdapat pada perlakuan $P_{2}$ yaitu 370 ekor dengan kerapatan kolektor $80 \%$ dan yang terendah terdapat pada perlakuan $P_{1}$ ( dengan kerapatan kolektor 50\%.) sebanyak 271 ekor larva/spat. Hasil uji $\mathrm{T}$ tes pada taraf $5 \%$ pada ke dua perlakuan P1 dan P2 menunjukan adanya berbeda nyata dimana $T$ hit $(1,561)<T$ tab $(2,228)$ 
namun tidak berpengaruh terhadap penempelan larva/spat tiram mutiara (Pinctada maxima) fase plantygrade. Untuk memperoleh jumlah larva/spat yang tinggi sebaiknya menggunakan substrat/kolektor yang lebih rapat dan padat, jika terlalu lebar kerapataannya akan menyebabkan larva lolos untuk menempel pada substrat/kolektor, karena larva pada fase plantygrade kebiasaan hidupnya akan mencari substrat yang padat untuk menempel/settle.

Nilai rata-rata kualitas air yang diperoleh selama penelitian yaiktu Suhu; $28,9{ }^{\circ} \mathrm{C}, \mathrm{PH} ; 7,1$. Salinitas 33 ppt dan DO ; 5,9 ppm. Sedangkan jenis pakan alami yang digunakan terdiri dari ; Isochrysis galbana, Chaetocheros simplex dan Nannochloropsis sp.

\section{DAFTAR PUSTAKA}

Alianto, 2006. Produktivitas primer fitoplankton dan keterkaitannya dengan unsur hara dan cahaya diperairan teluk banten. Tesis : Institut Pertanian Bogor.

Anonim, 2012, Petunjuk teknis budidaya mutiara . Balai budidaya laut Lombok, Nusatenggara barat.

Aprisanto, D.L., dan Budianto, M. 2011. Laporan Kegiatan Produksi Benih Tiram Mutiara (Pinctada maxima). Balai Budidaya Laut Lombok, Nusa Tenggara Barat.

Aprisanto. 2008. Pembenihan Tiram mutiara (Pinctada maxima). Teknisi Budidaya Laut Lombok (BBL). Sekonong.

ASBUMI (Asosiasi Budidaya Mutiara Indonesia), 1996.Buku Prosiding Seminar Nasional Budidaya kerang mutiara di Indonesia diselenggarakan di Auditorium, Dep. Pertanian Jakarta.

Eric, 2008. Kajian faktor lingkungan habitat kerang mutiara stadia spat di pulau Lombok Nusatenggara barat, Skripsi Fakultas Perikanan dan Ilmu Kelautan Institut Pertanian Bogor,

Hamzah, M.S. dan Kurnaen Sumadhiharga, 2002.Studi laju pertumbuhan dan kelangsungan hidup anakan kerang mutiara (Pinctada maxima) pada kedalaman yang berbeda di perairan Teluk Kombal, Lombok Barat. Makalah dipresentasikan Dalam : Kongres Nasional III, 21-24 Mei 2002 di Bali : 12 hal

Hamzah, M.S. Abd.Basir kaplale, Sangkala dan Rustam, 2005.Kelangsungan hidup anakan keran mutiara (Pinctada maxima) dan fenomena arus dingin di perairan Teluk Kombal, Lombok Barat.Dalam : Prosiding Pertemuan Ilmiah Tahun ISOI, Jakarta 10 - 11 Desember 2003. Anugra Nontji, W.B. Setyawan, D.E. Djoko Setiono, Pradina Purwati dan A. Supangat (editor) : Ikatan Sarjana Oseano-logi Indonesia : 171 - 178

Hamzah, M.S., 2007a. Prospek pengambangan budidaya kerang mutiara (Pinctada maxima) dan kendala yang dihadapi serta alternatif pemecahannya di beberapa tempat di kawasan perairan tengah Indonesia.Dalam: Proseding Aquaculture Indonesia, Masyrakat akuakultur Indonesia (MAI) Surabaya 5 - 7 Juni 2007. Purnomo, M. Fadjar, Dedy Yuniharto, Viwida Febriani dan Agung Sudaryono (eds.). Badan Penerbit Semarang : 212 - 223

Hefni, E, 2001. Telaah kualitas air bagi pengelolaan sumberdaya dan lingkungan perairan, Kanisius, Yogjakarta.

Mulyanto, 1987. Teknik budidaya laut tiram mutiara. Diklat Ahli usaha perikanan, Jakarta.

Newell G.E and Newell R.C. 1977. Marine Plankton. A Practical Guide. Fifth edition. Hutchinson, London. 343p.

O'Sullivan D. 1994. Hatchery Boost For Australia's Pearl Oyster. Fish Farm. Int., 21(2): 31-33.

Rahman, A. 2001. Teknik dan Analisis Usaha Produksi Spat Tiram Mutiara (Pinctada maxima) di PT. Buana Gemilang Hamparan Mutiara, Nusa Tenggara Bara. APHA (American Public Health Assosiation). 1979. Standard Methods for th Examination of Water and Wastewater. 17thd. APHA, AWWA (American Waste Water Assosiation) and WPCF (Water Pollution Control Federation). Poet City . Press. Balymore, Meryland

Raswin, 1972. Budidaya tiram. Direktorat jenderal perikanan Ambon, Departemen pertanian, Jakarta.

Rose R.A. 1990. A Manual of The Artificial Propagation of The Gold-lip or Silver-lip Pearl Oyster, Pinctada maxima (Jameson) From Western Australia. Fisheries Department Western Australia Marine Research Laboratories, P.O. Box 20, Nth Beach W.A. 6020. Commonwealth F.R.D.C., 41 
pp. Rose R.A and Baker S.B. 1994. Larva and Spat Culture of The Western Australian Silver or

Goldlip Pearl Oyster, Pinctada maxima Jameson (Mollusca: Pteriidae). Aquaculture: 126: 35-50.

Setyobudiandi, I. 1989. Moluska (Tiram Mutiara). Bahan Kuliah Sumberdaya Non Ikan.

Fakultas Perikanan dan Ilmu Institut Pertanian Bogor. Bogor.

Sudjana, 19991.Desain dan Analisis Eksperimen, Edisi III. Penerbit “Tarsito” Bandung : 415 hal

Sutaman., 1992. Kerang Mutiara. Teknik Budidaya dan Proses Pembuatan Mutiara. Penerbit

Kanisius. Yokyakarta : 93 hal.

Sutaman. 1993. Tiram Mutiara: Tehnik Budidaya dan Proses Pembuatan Mutiara.

Penerbit Kanisius. Yogyakarta: 93 hal.

Sutaman. 1993. Teknik Budidaya dan Proses Pembuatan Mutiara. Kanisius. Yogyakarta.

Tarigan, M.S.; Wenno, L.F dan Hamzah, M.S., 1991.Pengamatan hidrologi dalam kaitannya dengan budidaya biota laut di perairan Maluku Tenggara.Dalam Perairan Maluku dan Sekitarnya. Balai penelitian dan Pengembangan Sumberdaya laut, Puslitbang Oseanologi LIPI, Ambon : 127-134

Winanto, 2004. Memproduksi benih tiram mutiara. Penebae swadaya, Jakarta

Taylor. 1997. Biofouling dalam Kebiasaan Hidup Tiram Mutiara (Pinctada maxima). Jakarta. Sumber Media.

Taylor J.J, Rose R.A, Southgate P.C, Taylor, C.E. 1997. Effects of Stocking Density on Growth and Survival of Early Juvenile Silver-lip Pearl Oyster Pinctada maxima (Jameson) Held in Suspended Nursery Culture. Aquaculture 153: 31-40.

Tjahjo. 2004. Memproduksi Benih Tiram Mutiara (Pinctada maxima). Penebar Swadaya. Jakarta.

Winanto, D. 1999. Penyediaan Benih Tiram Mutiara (Pinctada maxima) di Laboratorium Balai Budidaya Laut.

Winanto, D. 2004. Budidaya Tiram Mutiara (Pinctada maxima) di Laboratorium Balai Budidaya Laut.

Winanto, D, dan B.S. Katiman. 1999. Laporan Hasil Rekayasa Teknologi Hasil Pemeliharaan dan Spat Tiram Mutiara (Pinctada maxima) di Laboratorium Balai Budidaya Laut. 